\title{
A View of Jungian Analysis in Aotearoa New Zealand
}

\author{
Chris Milton \\ Clinical Psychologist and Jungian Analyst, \\ AUCKLAND
}

\begin{abstract}
This paper traces something of the Jungian presence in Aotearoa New Zealand from the late 1930 s through the formal association of Jungian analysts in the late 1970 s to the present day. The Jungian presence in Aotearoa New Zealand is set within the context of international Jungian thinking. A particular understanding and practice of Jungian analysis is presented. In particular, two foci: individuation and its phenomenology, along with a definition of analysis and its expression in certain dialectics. Analysis is understood as the quest for individuation, whereby one becomes the authentic and autonomous author of one's own existence, through a professional interpersonal relationship. The analyst is understood to facilitate analysis by working out of their own autonomy, authenticity and authority - all consequences of their own individuation. Some aspects of the analytic process are described: the reductive - synthetic dialectic, the Promethean-Epimethean attitude, the presence interpretation dialectic and the openness - loyalty to insight dialectic.
\end{abstract}

\section{Waitara}

He whai haere tā tēnei pepa i ètahi whakarerenga iho a te Hungiana arā, Jungian taunga mai i Aotearoa Niu Tỉreni mai i te pito whakamutunga o ngā tau 1930s mai i ngā piringa porihanga ōkawa atu ki ngā kaitātari Hungiana i te whakamutunga o ngā tau 1970 tae noa mai ki ēnei rā. Ka poua te āta o te Hungiana i Aotearoa Niu Tīreni nei i roto i te whakaarohanga Hungiana whānui. Ka whakatauhia he momo tirohanga he momo mahi ā rātou, inā rā tōtika tonu te titiro ki ngā take e rua: te wehenga whaiaro, ōna ātanga me te aronga o te tātarihanga me tōna whakaputanga i rō ètahi matapakihanga. E mātau ana he rapunga whaiaro te tātarihanga, inā rā ka tau ki te tangata tonu te mana te rangatiratanga o tōna ake oranga mai i ngā whakapiringa ōkawa. E mātau ana mā te kaitātari e āwhina te tātaringa mai i te rapunga i tōna ake whaiaro, tōna ake mana me tōna rangatiratanga - te mutunga mai o tōna ake whaiaro. Ka whakamāramahia ētahi o ngā tirohanga o te tātarihanga: te whakamāmā - te kōrero tito, te tirohanga ā-Porometiana- à-Epimetiana, te āta - te whakamāori kōrero me te matanui - te mau ki te whaiwhai kōrero pono.

Milton, C. (2016). A view of Jungian analysis in Aotearoa New Zealand. Ata: Journal of Psychotherapy Aotearoa New Zealand, 20(2),129-142. DOI:10.9791/ajpanz.2016.12 ( New Zealand Association of Psychotherapists Inc. 
Keywords: Jungian analysis; Aotearoa; poetry; landscape; dislocation; loss; belonging

Analytical psychology, also called Jungian analysis, is a school of psychological thinking and therapy, which originated in the ideas of the Swiss psychiatrist C. G. Jung (26 July $1875^{-6}$ June 1961). What has been the history of analytical psychology in Aotearoa New Zealand, how prevalent is it, has it taken an Aotearoa New Zealand form?

I propose to say something on the history of analytical psychology/Jungian analysis in Aotearoa New Zealand and describe some aspects of my own thinking as someone who has practised and, hopefully, developed Jungian analysis in Aotearoa New Zealand. More specifically, I shall present some history, an understanding and phenomenology of individuation as well as a definition of the notion of analysis and elements of Jungian analytic practice.

\section{Analytical Psychology in Europe and the USA}

With the outbreak of World War II the two major centres of analytical psychology in Europe and the United Kingdom, Zürich and London, became separated from each other. This led to differing developments in theory - whereas the Zürich group tended to follow the unfolding development of Jung's own thinking, the London group engaged with Freudian, Kleinian and Independent Group thinking and assumed a more developmental tone. These schools of thinking have been variously described as classical and developmental schools respectively. In the same period, European analysts escaped the Nazis in Europe by emigrating to the United States of America. These analysts had a profound impact on the development of analytical psychology, with American analysts forming a significant proportion of the world's population of analysts. In 1985, Andrew Samuels, focusing mostly on the tension between the Zürich and London schools, distinguished three distinct traditions or approaches of "post-Jungian" psychology - classical, developmental and archetypal. This is a useful categorisation, but it does not address some of the American trends comprehensively, and it does not address more recent developments.

In brief, the classical approach attempts to remain faithful to what Jung himself proposed and taught. It is based on a view that the ego develops a particular attitude, which is then compensated for by that part of the psyche which is unconscious (which for ease I will hereafter risk reifying and call "the unconscious"). The ensuing confrontation with the unconscious causes tension that is ultimately resolved, if all goes well, by the emergence of a transcending symbol. This process, ongoingly repeated, is individuation. Clinically it utilises methods such as dream work and active imagination to facilitate the encounter with the unconscious.

The developmental approach is primarily associated with Michael Fordham and the Society of Analytical Psychology (SAP) in London. Arising to some extent out of a local rapprochement with psychoanalytic thinkers, this school differs from the classical by giving more emphasis theoretically to the development of personality. Elements of a developmental approach have also arisen in the thinking of analysts in Germany (of which Hans Dieckmann is an example). Mario Jacobi in Switzerland was part of a blending of Jungian and self- 
psychological thinking. In recent years there has been a strong rapprochement, from the Jungian side, with attachment theory, as is exemplified in the work and thinking of Jungian analyst Jean Knox. Clinically, the developmental school gives more attention to transference and countertransference than either the classical or the archetypal schools.

The archetypal school is quite small and can hardly be called a "school" at all. James Hillman's work reflects the archetypal approach. This approach decentres the progressive notion of individuation and replaces it with a less directional encounter between ego and archetypal images. Clinically, the archetypal approach is very mindful and respectful of images as they are on their own terms.

Elegant and popular though it is, this three-fold model of Samuels' does not take account of other approaches in analytical psychology, mostly USA based, such as Murray Stein and Donald Kalsched. These thinkers, whilst proposing something of a classical-developmental hybrid, argue for a trans-psychic (or spiritual) element to Jung's thinking. John Perry and others accent the place of complexes in psychological life. Both Robert Romanyshyn and South African-American Roger Brooke, not analysts but phenomenologists, dialogue phenomenology and analytical psychology.

\section{A Brief History of Analytical Psychology in Aotearoa New Zealand}

Analytical psychology has a presence in Aotearoa New Zealand going back almost 80 years. Grete Reiche Christeller was one of the earliest, if not the earliest, Jungian analyst in Aotearoa New Zealand. She was a German Jew born in Berlin in 1895 and she died in Wellington in 1964. She initially trained as a nurse and studied massage in Switzerland. She trained in Zürich in the early 1930 s and apparently analysed with Jung. Although her status as an analyst has been disputed by Thomas Kirsch (2000) she was made a member of the London-based SAP in 1949. As a younger person she practiced for a short time in Genoa, Italy, before emigrating to Aotearoa New Zealand in 1939. In Aotearoa New Zealand she lived, serially, in Auckland, Christchurch, and Wellington. She was one of the founders of the New Zealand Association of Psychotherapists (NZAP) in 1947 (Aigresse, 1964; Bell, 2012; Kirsch, 2000). New Zealand writer Bill Pearson and the poet James Keir Baxter (Millar, 2010) analysed with her as did Janet Frame. (It seems that the therapeutic effect for Janet was less than desired because Janet was seemingly unable to make free associations [King, 2000]. Christeller recommended to Janet that she have ECT treatment at Sunnyside Mental Hospital, which Janet did. Perhaps more helpfully, Christeller introduced Janet to Rilke's poetry [Weir, 2014]).

In 1977, five Australian Jungian analysts formed an Australian and New Zealand group that sought membership of the International Association for Analytical Psychology (IAAP), the international peak body for Jungian analysts. To an extent it nucleated around Rix Weaver, the first Australian to study with Jung. Attending the classically oriented C. G. Jung Institute in Zürich, she was the first Australian to be accepted as a member of the IAAP. The Australian and New Zealand Society of Jungian Analysts (ANZSJA), as it was finally styled, was granted group membership of the IAAP in 1977. Dr Dorothea Wraith, a New Zealand psychiatrist, joined ANZSJA in 1979. Dorothea had trained to become a Jungian analyst with the developmentally oriented SAP in London. Dale Dodd, an American clinical psychologist, 
had come to Aotearoa New Zealand in 1975. In 1978, he went to Santa Fe to train as a Jungian analyst with the Inter-Regional Society of Jungian Analysts. He returned to Aotearoa New Zealand in 1981, and finished up his training with Dorothea. By 1984, he and Dorothea were running Jungian interest activities and training Jungian analysts in Aotearoa New Zealand. The original group of trainees included Peter Reid and Wilson Daniel, both now deceased. Over the years members of other IAAP groups either returned to or migrated to Aotearoa New Zealand. Allan Bloore, Joy Ryan-Bloore, and Alison Thornton, who had trained in Zürich and, later, George Rodwell and Andrew Gresham (both SAP, London), and Chris Milton (SAAJA, Cape Town) joined ANZSJA in Aotearoa New Zealand.

In 2003, Dale Dodd, Mary Lane Dodd (his wife and also a clinical psychologist), and Chris Milton formed the Auckland Analytical Psychology Group (AAPG) and provided seminars to professionals from time to time. In 2005, Chris Milton launched a Jungian study group in Auckland which ran for just on two years. At about the same time clinical psychologists Marijke Batenburg, Chris Milton, and Rachael Feather established a Jungian seminar group to provide lectures by visiting international Jungians.

The ANZSJA training in both Australia and Aotearoa New Zealand gradually moved to a more formal model and there were cohort intakes in 1997,1998, 2006, and 2013 ( Anon, n.d.; Kirsch, 2000). Although in recent years we have seen the deaths of Wilson Daniel and Dale Dodd, today in Aotearoa New Zealand there are a total of ten Jungian analysts: Jill Yielder, Alison Thornton, Joy Ryan-Bloore, Siobhan Collins, Rachael Feather, Sheena Gallocher, Andrew Gresham, Chris Milton, Allan Bloore, and Barbara Bassett. The variety of approaches in analytical psychology are found represented within this group.

There have been Jungian initiatives in Aotearoa New Zealand by people who are not Jungian analysts. In 1993, Ian Laird set up the C. G. Jung Foundation in Auckland (Bowater, n.d.) and, also in Auckland, Lea Holford has taught transpersonal psychology and Jungian thinking. Sandplay, which is a specific therapy method based in Jungian thinking, is still relatively new to Aotearoa New Zealand but does have a presence. There are a few Aotearoa New Zealand practitioners who are Independent Candidates with the International Society of Sandplay Therapists.

All the varieties of Jungian thinking are found in Aotearoa New Zealand: classical, developmental, archetypal, and others. ANZSJA's training is designed to try and facilitate trainees to become the analysts that they are rather than follow a school.

\section{Personal View}

I shall present something of my personal view of Jungian analysis, although this is neither exhaustive of my thinking nor completely representative of the spectrum of Jungian thinking in Aotearoa New Zealand. My own view is something of a blend with strong elements of both the classical and developmental approaches, but also with a pronounced sensitivity to spirituality and the transpersonal.

My understanding is that individuation and analysis are related. Analysis is a process that facilitates individuation. As I see it, analysis arises when the analyst is interacting and working from the point in their own psyche at which the ego and the unconscious meet and interact in a meaningful way. Thus individuation occurs in the relationship and interaction 
between analyst and analysand from a functional place of interaction between the analyst's consciousness and unconscious. To the extent that the analyst is individuated, the analyst's capacities for autonomy, authenticity, and authority serve the analysand in the analytic process.

I believe that this understanding is implicitly present in the classical and developmental approaches. My own evolution as an analyst has involved an attempt to integrate the classical and developmental ways of thinking as well as incorporating a very strong grounding in existential phenomenology and transpersonal psychology. I shall commence by giving a short summary of the classical and developmental approaches.

Classically, Jung believed that our inevitable one-sided psychological development is compensated for by a natural and progressive process which can be described under the rubric of "individuation". The personality is the dynamic combination of both ego and the unconscious. In the early part of the 2oth century Jung (1971/1923) became interested in the habitual attitude of the ego which is compensated for by dream images, symptoms, and even psychosis. His notion was that the ego is the centre of consciousness, but not the centre of the personality.

The unconscious consists of both a personal unconscious, into which anxiety-generating impulses, affects, images, and experience are "repressed" and a collective unconscious, which is not repressed but has never before been conscious to the individual.Compensating possibilities-of-being arise out of the unconscious to challenge the ego attitude to transform. These possibilities-of-being primarily find expression in images that are based in "archetypes". Archetypes are dispositions that structure our experience and behaviour.

When the ego is challenged by the unconscious, great tension and defendedness may arise. It seems as if there is no way that these quite different ways-of-being can combine with and be appropriated to consciousness. However, Jung understood that there was a capacity, shared by all human beings, to transcend and incorporate something of both the conscious and unconscious. The product of this capacity is the symbol, which we may define as the "best possible description or formulation of a relatively unknown fact (i.e. a fact that is both conscious and unconscious)" (Jung, 1971/1923, para. 841).

The Self is the ground of the personality and also the central organising archetype. The Self is experienced as the centre of the personality (Brooke, 1991) and is implicated in individuation in that it drives and shapes it.

Individuation itself is the continual process of encounter between ego attitude and unconscious, the challenge this generates, and, hopefully, the conflict's transcendence and the ego's transformation. Individuation thus consists of the evolving relationship between ego and Self. Furthermore, individuation is always manifest in the changing shapes of our embeddedness in relationship to others.

Having said all that - for me - the classical understanding needs to be infused with the workmanlike concepts of the developmental approach, and even of psychoanalysis. I believe that a thorough understanding of psychoanalytic concepts and practices (especially those around transference and attachment theory) is essentially useful to Jungian analysis.

The developmental approach, on the other hand, has initially been much more interested in the early formation of the sense-of-self. The developmental approach eschewed the classical interest in the belief that ontogeny recapitulates phylogeny. The classical approach 
saw the development of the ego (ontogeny) reflected in the hero myth (phylogeny). Contrariwise, the developmental approach relied mostly on empirical clinical and infant observation to form its theory. This thinking was largely based on Michael Fordham's notion of an early "primal self" which unpacked and developed the personality through a process of deintegration, engagement with the external reality, and reintegration to incorporate the realised and consciousness-building deintegrate, thus developing the personality. This became the dominant developmental approach to individuation. It is highly compatible with Kleinian, Winnicottian, and Bionic thinking. Theoretically, the "deintegrationreintegration" cycle is not too dissimilar from Bion's notions of preconception-conception. Clinically, the accent fell more on transference and countertransference and the developmental school was initially highly critical of the classical approach, regarding it as defensive in its focus on dreams and active imagination. (Furthermore, Fordham articulated the notion of "defences of the self" which manifest as massive splitting and projective/ introjective mechanisms, including projective identification which forms something of a conceptual bridge to psychoanalysis.)

There are two foci that I find relevant and which greatly inform my own understanding and practice of Jungian analysis - these are:

- Individuation and its phenomenology

- The definition of analysis and its expression in dialectics

\section{Individuation and its Phenomenology}

I understand that analysis (and hence the analysand's individuation) occurs in the relationship and interaction between analyst and analysand. My personal and clinical experience has led me to develop a particular understanding of individuation. I have come to believe that, whilst usually the Self is seen as the centre of the personality, it is instead more useful and meaningful to locate the relationship between ego and the Self as the functional centre of the personality. This accents the role of both the other and the Other in individuation. I think that when we can live from out of a transcending dialogue between ego and Self then we live relationally with true authority, authenticity, and autonomy. In conducting analysis the analyst ideally relates with the analysand from out of this functional centre of interaction between the analyst's own consciousness and own unconscious.

It also needs to be said that in Jung's own understanding, individuation is ultimately about not being completely adapted to the collective. Although individuation commences as a process of adaptation to the collective, by mid-life this may change so that the true authority, authenticity and autonomy of the personality may emerge. In one sense this situates individuation as a process that is ultimately subversive of culture. Jung believed that there is a price or "ransom" that we must pay for this withdrawal and subversion. This ransom takes form of a creative contribution to culture:

[The individuating person] ... must offer a ransom in place of himself ( $\mathrm{sic}$ ), that is, he must bring forth values, which are an equivalent substitute for his absence in the collective, personal sphere ... (Jung, 1977/1948, para. 1094f.) 
Individuation is an ongoing process so it is not strictly correct to speak of the "outcome"of individuation. Although it is often framed in theoretical terms I have become interested in the phenomenology of individuation and I believe it helps to describe some aspects of its phenomenology. What follows is my own preliminary articulation of the phenomenology of individuation:

There is a knowing of one's "place" in the world. One is unimportant, but being unimportant is itself unimportant. There is also a heightened awareness of what one's conscious sense-of-self does contribute to activities engaged in. There is consciousness of an otherness, mostly within oneself (the Self) and a feeling of partnership with this otherness which provides a deep and mysterious source. Ideas and feelings unexpectedly emerge out of this source. One is able to observe and accept these. In another, possibly more everyday way, one experiences the giveness of certain abilities, such as a capacity to sing or to come up with the "right" thought. Without claiming them as one's own there is an awareness of, and an openness to, receiving ideas, feelings, and creative impulses, from this deep source of otherness. This appreciation extends from the depths of the psyche to include other people as such a source - so it has a parallel influence from relationships with others. The ego is not only receptive to but collaborates with the deep source of ideas, feelings, and creative impulses but it still knows that it is not itself their origin. Furthermore, the ego surrenders some, but not all, of its will and direction taking to this deep source. Working together with the deep source the ego becomes a co-author of the personality's activities. With the relativisation of the ego there is somewhat of a decrease in anxiety and an increase of letting-be-ness. Along with these processes there is an increase in one's self-confidence and an increased sense of autonomy, authenticity and authority. Nonetheless, the autonomy is not individualistic, the authenticity is more than egoic and the authority is true authority not authoritarianism.

As an important aside I wish to say that my thinking has been strongly influenced by and forged within the challenge of cultures that meet in Aotearoa New Zealand. Dominantly scribed within the cultural tropes of biculturalism and the Treaty of Waitangi there is a very practical attempt to clear a space where one meets the "other" and the "Other", i.e., the literal other but also otherness, the Self, which provides a deep and mysterious source. This not insignificant fact requires a treatment of its own which it cannot here receive.

\section{Definition of Analysis}

I need to say, before going further, that for me analysis is a process which is profoundly relational, phenomenological, and also ultimately transpersonal. I suspect that by focussing on certain more technical particulars the sense and ambience of this may be obscured.

I shall commence my attempt to articulate and define analysis by quoting a more general perspective of Jung's: "Man's task is to become conscious of the contents that press upward from the unconscious" (1973, p. 28). Analysis might be seen as: 
- The quest to become the authentic and autonomous author of our own existence;

- Through a professional interpersonal relationship;

- That facilitates the transformative encounter of the ego with the Self (or, perhaps, with the unconscious).

If, as I have argued, individuation means that one lives from out of the relationship between ego and the Self then analysis might be seen as a process whereby the analysand comes to do that through working relationally with an analyst who has more or less some experience of, and capacity for, living and working out of that position.

Personally I do not advocate for a monistic and utopian model of analysis. Instead I understand analysis as a fluctuating process in which an analytic state-of-being is "found and lost" as the work is undertaken. It may be more accurate to say that a state of analysis exists when the accent of the professional interpersonal interaction shifts towards the analysand's encounter with their unconscious. Analysis emerges from the ground of narrative and formulation but is not itself the same as, or reducible to, narrative and formulation (Milton, 2014).

A state of analysis tends to occur when an analyst empathically attunes to the analysand and allows their own psychological responsiveness to become entrained to the analysand's productions or state-of-being. In Jungian analysis the analyst notices the resistances, the transference/countertransference eruptions and out-picturings of psychological life and seeks to facilitate the analysand's encounter with the unconscious material however it may be manifested.

The phrase that I use above, "an analyst listens and empathically attunes to the analysand and allows their own psychological responsiveness to become entrained to the analysand's productions" is in some respects much too tame. This can be a relatively quiet experience and produce an enveloping ambience within which the experience of analyst and analysand resonate but it may be a more intense encounter. In "The Psychology of the Transference", Jung wrote:

The doctor, by voluntarily and consciously taking over the psychic sufferings of the patient, exposes himself to the overpowering contents of the unconscious and hence also to their inductive action ... The patient, by bringing an activated unconscious content to bear upon the doctor, constellates the corresponding unconscious material in him. (1946/1966, p. 176)

In an earlier writing, “The Problems of Modern Psychotherapy” Jung had said something similar but with an even more dramatic quality:

For two personalities to meet is like mixing two different chemical substances: if there is any combination at all, both are transformed. In any effective psychological treatment the doctor is bound to influence the patient; but this influence can only take place if the patient has a reciprocal influence on the doctor. You can exert no influence if you are not susceptible to influence. (1929/1966, p. 71) 
Jungian analysis is foundationally interpersonal and relational. In one sense I have come to view analysis as a set of dialectics within an archetypal/interpersonal field in which the analyst and analysand are deeply and mutually implicated. Some of these dialectics are the:

- Reductive versus synthetic perspectives

- Promethean-Epimethean attitude

- Use of presence versus interpretation

- Openness versus loyalty to insight

\section{Reductive versus synthetic}

Broadly speaking analysis has two merging but theoretically separable registers: the freeing of obstructed possibilities-of-being and the pursuit of novel possibilities-of-being. The former is best epitomised by psychoanalysis and developmental Jungian analysis and is more reductive, whereas the latter is epitomised by classical Jungian analysis and is more synthetic. Both lead towards true authority, authenticity and autonomy. Jungian analysis occurs in the dialectic between the reductive and the synthetic registers. Kalsched formulated this as analysis conducted with one metaphoric eye closed "focused on the inner world of dreams and the mythopoetic images of imagination, and one eye open, focused outwardly on the harder edges of material reality, including the realities of human relationship" (2013, p. 6).

From the analyst's side I have articulated this in the image of what I have called "the mystic in a bowler hat". With regard to analysis:

I suggest that we allow the transpersonal register to be the ground of this work, whilst at the same time attempting to forge a workmanlike analytic praxis ... I shall image pragmatic and responsible practice as a suite of city clothes, including bowler hat and umbrella, worn by a mystic, hence: the mystic in a bowler hat (Milton, 2000, unpublished work).

\section{Promethean-Epimethean attitude}

The Promethean-Epimethean Attitude is a notion which I first articulated in 2003 in a presentation entitled, "The Promethean-Epimethean Attitude and its Use in the Transference/Counter-transference" as a seminar presented to the AAPG. The notion can be visualised as set of orthogonal axes, one the Promethean attitude, the other the Epimethean attitude, which produce a metaphoric space within which we operate analytically between anticipation and discovery.

In and of itself the Promethean attitude is present in analysis when the analyst carefully anticipates the effect of a contemplated intervention. In its negative form the Promethean attitude becomes a dreadful and persecutory analytic "superego" through which an analyst focuses on his/her own shortcomings. Used in isolation it is problematic as it leads to trying to conduct analysis using "memory and desire" (Bion, 1967/1988).

By contrast, the Epimethean attitude is oriented towards the discovery of truth by consequences. It is present in analysis when the analyst learns something from the aftereffects of an actual intervention. We use the Epimethean attitude by noticing and interpreting 
the analysand's response to our actions/enactments. In particular, this calls for our analysis of the analysand's derivative "comments" on our conduct of the analysis. In its worst form the Epimethean attitude blends negatively with the Promethean superego and becomes a masterful but arid post hoc application of the hermeneutic of suspicion to all the events of analysis thus destroying their symbolic density.

Ideally these attitudes combine dialectically to become the Promethean-Epimethean attitude which, as I have said, is a particular form of metaphoric space, much like the notion of transitional space formed between and by the axes of reality and phantasy, but instead formed between the axes of our capacity for anticipation and our capacity to assess consequences (especially as communicated by unconscious communications).

\section{Interpretation versus presence}

The analytic technique of presence versus interpretation is something that I introduced in 2004 in a presentation entitled, "Interpretation or Presence: The Use of the Body in Overcoming Resistance in Analysis" also as part of a seminar presented to the AAPG. Interpretation is the original technical tool of traditional psychoanalysis. From the traditional psychoanalytic perspective the analyst specifically notices the interruptions and gaps (i.e., resistances) and transference eruptions which disrupt the fundamental rule of free association. On the basis of the manifest content and the fact of the resistance or transference the analyst infers the nature of, and then facilitates the emergence of, the unconscious by interpretation. Traditionally, interpretation is a process whereby the manifest content of the analysand's productions is back-translated into the latent content of the unconscious using an understanding of the mechanisms of displacement, condensation, symbolisation and secondary revision. More usefully interpretation does more:

- It gives some sense of the unconscious material itself;

- It understands and empathically holds the distress, anxiety, guilt etc. that unconscious material fosters and;

- It grasps the defences mounted against the unconscious material in order to avoid the discomfort which it produces.

Interpretations are also made with reference to the object or objects of this triad: people experienced in the past, people experienced in the present and, most particularly, the analyst (transference).

The manifesting of the unconscious material and the empathic containment of the anxiety etc. which it engenders leads to a change in the experience of the anxiety and modification of the defences used against it. In this way, in the traditional psychoanalytic model, transformation is effected. In more recent years several additional axes or vertices have been added to this basic model. In particular, the general importance of the object (or Other); attachment dynamics; the vital importance of mirroring, valuing, and selfobject provision have all become more prominent. The very aim of traditional psychoanalysis has been recast in various ways. For instance, Bion seemed to formulate analysis as the pursuit of truth, and Ogden expanded Freud's definitionary statement: "Perhaps psychoanalysis might be viewed as involving a recognition not only of transference and resistance, but also 
of the nature of the intersubjective field within which transference and resistance are generated" (1996, p. 885).

Be all that as it may, there are some analysands for whom the use of interpretation does not work, and I am not here speaking of analysands who are pre-analytic or who have a dominantly narcissistic organisation and therefore need selfobject provision. I am, instead referring to analysands for whom emotion is unconscious and for whom interpretation, in its more intellectual aspects, serves to keep that emotion unconscious rather than help it enter consciousness. In seeking to engage with this I shall turn to a consideration of the body.

Near the beginning of his 1935 paper, "Principles of Practical Psychotherapy" Jung made the observation that: "One of the fundamental antinomies is the statement that psyche depends on the body and body depends on psyche" (1935/1966). Taking this idea further, psychoanalyst Braatøy (1954) has argued that analysts need to cultivate a capacity to register an analysand's psychological life within their own bodies and thus help make emotions available to the analysands. In this way the body becomes more than a means of registration it also becomes a vehicle for interpersonal/intersubjective transmission, or "presencing", of emotion registered in the countertransference.

My own experience, especially with clients who have an obsessional character structure, and who are therefore prone to intellectualisation over emotional experience, is that the traditional access to the unconscious via empathic enquiry and interpretation is less effective than the analyst's empathic bodily resonance followed by "presencing" of unconscious emotion to the analysand. Just how one performs "presencing" is not yet fully clear to me, although it does involve the analyst feeling emotion and allowing its evident bodily presence in the analyst's musculature, prosody, and gesture. It is a process which cries out for phenomenological exploration.

I am not making working by presencing a rule but rather suggesting that the interpretation-presence dialectic forms part of a dyad in which whichever pole is appropriate becomes foregrounded. Discussion of how "presencing" risks being the analyst's own projective identification and what to do about it cannot be explored in this paper.

\section{Openness versus loyalty to insight}

Despite what I have said above, I have come to believe that the analyst's analytic insight is a valuable tool in the conduct of analysis. Whilst in general I endorse maintaining the therapeutic alliance (Bibring, 1937) or healing rupture and also working in an empathically attuned interpersonally oriented and sensitive way (Safran, 2003; Safran, Muran, Samstag \& Winston, 2005; Safran \& Muran, 2006; Safran, Muran \& Eubanks-Carter, 2011), I also think that the analyst needs to maintain a degree of confidence in, and loyalty towards, their own views and be prepared to pursue interpretations, and present the analysand with a firm view. The therapeutic alliance is ambiguous and is thus easy ground from which an analysand can coerce the analyst to collude with their own, sometimes defensive, self-analysis. Some analysands are prone to try and take control of the analysis (Milton, 2012). In general, these analysands are knowledgeable about analysis and make appeals to current findings and contemporary thinking about analysis (especially relational psychoanalytic thinking). In analysis they argue that the analyst is "old school", does not adequately understand them 
(which of course he/she may not) or that the analyst is being too interpretive or theory based. Furthermore, they try to insinuate themselves into directing the analysis (which they treat superficially as a cooperative endeavor but which they shape into one which disqualifies the analyst) so that the analyst becomes more uncertain, tentative and restorative.

The analysand may experience the analyst's firm expression of alternative views as quite confrontational but in maintaining autonomy and loyalty to their own authenticity and authority the analyst does not only proffer the insight but also demonstrates faith in the reparation (not restoration) of relationship that is challenged by difference. The analyst can be wrong, so too may the analysand, this way they get to work it out together.

I think that loyalty to analytic insight as well as openness/uncertainty about what the analyst "knows" about the analysand work best by forming a dialectic in which there is an alternation of foregrounding and backgrounding these two vertices.

These three dialectics all serve to foster the encounter of the ego with the unconscious. The more that the analyst is able to work from their own individuatory encounter between ego and Self the more the process is likely to be authentic and authoritative.

\section{Conclusion}

Analytical psychology emphasises the importance of the human quest for wholeness. Different parts of the world have seen different articulations of Jungian thinking and practice. The earliest Jungian presence in Aotearoa New Zealand was in the late 1930 s but it did not become part of a formal association until 1979. Today there are ten Jungian analysts in Aotearoa New Zealand and seven Aotearoa New Zealand trainees with ANZSJA. There are other Jungian oriented practitioners in Aotearoa New Zealand who are not Jungian analysts.

Drawing on both the classical and developmental approach of analytical psychology as well as psychoanalysis, I have shaped my own understanding and practice of Jungian analysis. In particular, I have presented two foci: individuation and its phenomenology along with a definition of analysis and its expression in certain dialectics.

Crucially, I understand individuation as living to a degree, from out of the relationship between ego and the Self as the functional centre of the personality. I understand analysis as the quest to become the authentic and autonomous author of our own existence through a professional interpersonal relationship that facilitates the transformative encounter of the ego with the Self or the unconscious. I believe that the analyst facilitates analysis by working out of their own autonomy, authenticity and authority - all consequences of their own individuation. Some of the analytic process is facilitated by various dialectics: the reductive - synthetic dialectic, the Promethean-Epimethean attitude, the presence - interpretation dialectic and the openness - loyalty to insight dialectic.

My attempts here are far from exhaustive but they provide an introduction to the direction that some Jungian thinking and practice is taking in Aotearoa New Zealand. 


\section{CHRIS MiLton}

\section{References}

Anon. (n.d.). Retrieved from http://anzsja.org.au/history/

Aigrisse, G. (1964). Obituary notices. Journal of Analytical Psychology, 9, 171-178

Bell, L. (2012). In L. Bell \& D. Morrow (Eds.), Jewish lives in New Zealand: A history, (pp. 311-312). Auckland, Aotearoa New Zealand: Godwit.

Bibring, E. (1937). Contribution to the symposium on the theory of the therapeutic results of psychoanalysis. International Journal of Psychoanalysis, 18, 170-189.

Bowater, M. (n.d.). Dreamwork in New Zealand. Retrieved from http://dreamtalk.hypermart.net/ international/new_zealand_english.htm

Braatøy, T. (1954). Fundamentals of psychoanalytic technique. New York, NY: John Wiley \& Sons.

Brooke, R. (1991). Jung and phenomenology. London, United Kingdom: Routledge.

Jung, C. G. (1966). Problems of modern psychotherapy. (R. F. C. Hull, Trans.). In H. Read et al.

(Series Eds.), The collected works of C.G. Jung (Vol.16, 2nd ed.). Princeton, NJ: Princeton

University Press. (Original work published 1929)

Jung, C. G. (1966). Practice of psychotherapy (R. F. C. Hull, Trans.). In H. Read et al. (Series Eds.), The collected works of C.G. Jung (Vol.16, 2nd ed.). Princeton, NJ: Princeton University Press. (Original work published 1935)

Jung, C .G. (1966). The psychology of the transference (R. F. C. Hull, Trans.). In H. Read et al. (Series Eds.), The collected works of C.G. Jung (Vol.16, 2nd ed.). Princeton, NJ: Princeton University. (Original work published 1946)

Jung, C. G. (1971). Psychological types. (R. F. C. Hull, Trans.). In H. Read et al. (Series Eds.), The collected works of C.G. Jung (Vol. 6). Princeton, NJ: Princeton University Press. (Original work published 1923)

Jung, C. G. (1973). In J. Jacobi (Ed.), C.G. Jung: Psychological reflections. A new anthology of his writings, $1905-1961$ (R. F. C. Hull, Trans.). Princeton, NJ: Princeton University Press.

Jung, C. G. (1976). The symbolic life (R. F. C. Hull, Trans.). In H. Read et al. (Eds.), The collected works of C. G. Jung (Vol.18, pp. 267-290). Princeton, NJ: Princeton University Press. (Original work published 1954)

Kalsched, D. (2013). Trauma and the soul. London, United Kingdom: Routledge.

King, M. (2000). Wrestling with the angel: A life of Janet Frame. Auckland, Aotearoa New Zealand: Viking.

Kirsch, T. B. (2000). The Jungians: A comparative and historical perspective. London, United Kingdom: Routledge.

Millar, P. (2010). No fretful sleeper: A life of Bill Pearson. Auckland, Aotearoa New Zealand: Auckland University Press.

Milton, C. (2000). The mystic in the bowler hat: Notes on a psychoanalytically augmented model of analytical psychology. Paper submitted in partial fulfilment for Ph.D. in Psychotherapy, Rhodes University, Grahamstown, South Africa.

Milton, C. (2003). The Promethean-Epimethean Attitude and its use in the transference/countertransference. Seminar presented to the Auckland Analytical Psychology Group. Auckland, Aotearoa New Zealand.

Milton, C. (2004). Interpretation or presence: The use of the body in overcoming resistance in analysis. Seminar presented to the Auckland Analytical Psychology Group. Auckland, Aotearoa New Zealand. 
Milton, C. (2012). A psychodynamically informed approach to the challenges of psychotherapy with a certain sub-type of narcissistic personality disorder. Journal of the New Zealand College of Clinical Psychologists, 22(2), 45-53.

Milton, C. (2014). Figure and ground: An enquiry into what analysis is. Ata: Journal of Psychotherapy Aotearoa New Zealand, 17(2),189-199. doi: 10.9791/ajpanz.2013.18

Ogden, T. H. (1996). Reconsidering three aspects of psychoanalytic technique. The International Journal of Psychoanalysis, 77, 883-899.

Safran, J. D. (2003). The relational turn, the therapeutic alliance and psychotherapy research: Strange bedfellows or postmodern marriage? Contemporary Psychoanalysis, 39(3), 449-475. doi:1 $0.1080 / 00107530.2003 .10747215$

Safran, J. D., Muran, J.C., Samstag, L., \& Winston, A. (2005). Evaluating alliance-focused intervention for potential treatment failures. Psychotherapy, 42(4), 532-545. doi: 10.1037/0033$3204 \cdot 42.4 \cdot 512$

Safran, J. D. \& Muran, J.C. (2006). Has the concept of the alliance outlived its usefulness? Psychotherapy, 43(3), 286-291. doi: 10.1037/0033-3204-43.3.286.

Safran, J. D., Muran, J. C., \& Eubanks-Carter, C. (2011). Repairing alliance ruptures. Psychotherapy, $48(1)$, 80-87. doi: $10.1037 /$ a0022140

Samuels, A. (1985). Jung and the Post-Jungians. London and New York: Routledge.

Weir, J. (2014).James K. Baxter complete prose volume 4. Retrieved from http://nzetc.victoria.ac.nz/ $\mathrm{tm} /$ scholarly/tei-Bax4Pros-t1-body-d6-d1.html

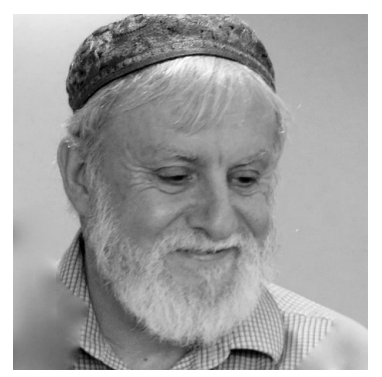

Dr Chris Milton is both a clinical psychologist and a Jungian analyst with a private practice in Auckland. He currently devotes most of his time to adult analysis and the supervision of clinicians. He also has extensive experience of working with children, adolescents, and their families. Chris is involved in the training of Jungian analysts in Australia and Aotearoa New Zealand and is a Training Analyst with the Australian \& New Zealand Society of Jungian Analysts (ANZSJA). Chris has a developed sense of the importance of phenomenology and has for a long time served on the editorial board of the online Indo-Pacific Journal of Phenomenology. Chris has published in the areas of infant mental health, psychoanalytic processes, the cultural complex, and well-being. He maintains an interest in spirituality and transpersonal psychology especially the phenomenology of individuation. Contact details: chris.milton@ xtra.co.nz . 